\title{
Xanthomonas campestris Diffusible Factor Is 3-Hydroxybenzoic Acid and Is Associated with Xanthomonadin Biosynthesis, Cell Viability, Antioxidant Activity, and Systemic Invasion
}

\author{
Ya-Wen He, ${ }^{1,2}$ Ji'en Wu, ${ }^{1}$ Lian Zhou, ${ }^{2}$ Fan Yang, ${ }^{1}$ Yong-Qiang He,${ }^{3}$ Bo-Le Jiang, ${ }^{3}$ Linquan Bai, ${ }^{2}$ Yuquan Xu, ${ }^{2}$ \\ Zixin Deng, ${ }^{2}$ Ji-Liang Tang, ${ }^{3}$ and Lian-Hui Zhang ${ }^{1}$ \\ ${ }^{1}$ Institute of Molecular and Cell Biology, 61 Biopolis Drive, Singapore 138673; ${ }^{2}$ State Key Laboratory of Microbial Metabolism \\ and National Center for Molecular Characterization of GMOs, School of Life Science and Biotechnology, Shanghai Jiao Tong \\ University, Shanghai 200240, China; ${ }^{3}$ State Key Laboratory for Conservation and Utilization of Subtropical Agro-bioresources, \\ Guangxi University, Nanning 530004, China
}

Submitted 6 February 2011. Accepted 8 April 2011.

\begin{abstract}
Xanthomonas campestris pv. campestris produces a membrane-bound yellow pigment called xanthomonadin. A diffusible factor (DF) has been reported to regulate xanthomonadin biosynthesis. In this study, DF was purified from bacterial culture supernatants using a combination of solvent extraction, flash chromatography, and high-performance liquid chromatography. Mass spectrometry and nuclear magnetic resonance analyses resolved the DF chemical structure as 3-hydroxybenzoic acid (3-HBA), which was further confirmed by synthetic 3-HBA. Significantly, bioassay and in silico analysis suggest that DF production is widely conserved in a range of bacterial species. Analysis of DF derivatives established the hydroxyl group and its position as the key structural features for the role of DF in xanthomonadin biosynthesis. In addition, we showed that DF is also associated with bacterial survival, $\mathrm{H}_{2} \mathrm{O}_{2}$ resistance, and systemic invasion. Furthermore, evidence was also presented that DF and diffusible signaling factor have overlapping functions in modulation of bacterial survival, $\mathrm{H}_{2} \mathrm{O}_{2}$ resistance, and virulence. Utilization of different mechanisms to modulate similar virulence traits may provide $X$. campestris pv. campestris with plasticity in response to various environmental cues.
\end{abstract}

The genus Xanthomonas is one of the most ubiquitous groups of plant-associated bacterial pathogens. Members of this genus have been shown to infect at least 124 monocotyledonous and 268 dicotyledonous plant species, many of which are economically important crops or plants (Leyns et al. 1984). A characteristic feature of the genus Xanthomonas is the production of yellow, membrane-bound pigments called xanthomonadin (Starr 1981). The presence of the pigments has become a useful chemotaxonomic and diagnostic marker for Xanthomonas spp. (Schaad and Stall 1988; Starr and Stephens

Y.-W. He and J. Wu contributed equally to this work.

Corresponding authors: Y.-W. He; E-mail: yawenhe@sjtu.edu.cn; L.-H. Zhang; E-mail: lianhui@imcb.a-star.edu.sg

* The $\boldsymbol{e}$-Xtra logo stands for "electronic extra" and indicates that seven supplementary figures and two supplementary tables are published online. Also, Figure 6 appears in color online.
1964). The xanthomonadins were initially thought to be carotenoids. However, further characterization has demonstrated that they represent a unique group of halogenated, arylpolyene, water-insoluble pigments that are associated exclusively with the outer membrane of the bacterial cell wall (Andrewes et al. 1976; Stephens et al. 1963). Moreover, xanthomonadins from different Xanthomonas spp. differ in bromination and methylation patterns, and this is useful for identifying members of the same genus (Starr et al. 1977).

Although xanthomonadins are not essential for the bacterial in planta growth (Durgapal 1996; Poplawsky et al. 1993; Tsuchiya et al. 1982), several lines of evidence show that xanthomonadins protect the pathogen from photooxidative damage. Pigment-deficient mutants from several Xanthomonas spp., including Xanthomonas juglandis, $X$. oryzae pv. oryzae, and $X$. campestris pv. campestris, were found to be more susceptible to photooxidative damage than their corresponding wild-type parental strains (Jenkins and Starr 1982; Poplawsky et al. 2000; Rajagopal et al. 1997). In addition, xanthomonadins were found to protect egg-phophatidylcholine lipsomes against peroxidation damage (Rajagopal et al. 1997). Furthermore, disruption of xanthomonadin production in X. campestris pv. campestris B-24 by transposon mutagenesis caused an approximately 100-fold decrease in bacterial epiphytic survival rate following exposure to high-intensity light (Poplawsky et al. 2000). Taken together, these findings have established the role of xanthomonadins in maintaining the ecological fitness of Xanthomonas spp. by protecting bacterial cells against photooxidative stress.

Early genetic analysis reported that xanthomonadin biosynthesis is encoded by a $25.4-\mathrm{kb}$ genomic region that contains seven transcriptional units (pigA to pigG) in $X$. campestris pv. campestris (Poplawsky and Chun 1997; Poplawsky et al. 1993). A similar pig cluster was also reported in $X$. oryzae pv. oryzae (Goel et al. 2002). Subsequent genome sequence analysis of $X$. campestris pv. campestris strains ATCC33913, 8004, and B100 showed that the pig cluster consists of 22 open reading frames (ORF), which may constitute part of a novel type II polyketide synthase pathway involved in biosynthesis of xanthomonadins (da Silva et al. 2002; Qian et al. 2005; Vorhölter et al. 2008).

Evidence has emerged that a diffusible factor (DF) is implicated in the regulation of xanthomonadin and exopolysaccha- 
ride (EPS) production in $X$. campestris pv. campestris. Null mutation of pigB in $X$. campestris pv. campestris B24 abolished the production of xanthomonadins and DF, and resulted in impaired production of EPS (Poplawsky and Chun 1997). Subsequent study with the pigB mutants detected a significant reduction in epiphytic survival rate, and a decrease in infection of natural host via hydathodes (Poplawsky and Chun 1998). Particularly noteworthy is that xanthomonadin and EPS production in the $\operatorname{pig} B$ mutants were restored in the presence of DF-producing strains, or by addition of partially purified DF, suggesting that DF might act as a signal for activation of xanthomonadin and EPS production.

DF was predicted to be a butyrolactone based on mass spectrometry (MS) analysis (Chun et al. 1997). However, a recent study showed that synthetic butyrolactone had no effect on xanthomonadin or EPS production, indicating that natural DF produced by $X$. campestris is not butyrolactone (Yajima et al. 2010). In addition, our preliminary analysis with a range of butyrolactones from Streptomyces spp. also did not identify any reported DF-like activity. To determine the biological functions of DF, we set out to purify and characterize the chemical structure of DF. Based on the findings that the gene $x a n B 2$, which encodes a putative pteridine-dependent deoxygenase, is needed for the production of DF signal (Poplawsky et al. 2005), we developed a reporter strain for detection and semiquantitative analysis of DF activity, which facilitated the purification and characterization of DF. In addition, functional analysis showed that DF plays a key role in regulating xanthomonadin biosynthesis, bacterial survival, $\mathrm{H}_{2} \mathrm{O}_{2}$ resistance, and bacterial systemic invasion. Furthermore, we showed that DF and diffusible signaling factor (DSF) signals have a cumulative effect on modulation of $X$. campestris pv. campestris survival, oxidative stress resistance, and systemic invasion.

\section{RESULTS}

\section{$X$. campestris pv. campestris strains 8004 and XC1 produce the diffusible signal DF \\ to regulate xanthomonadin production.}

Previously, Xcc4014 (xanB2) was shown to be responsible for the biosynthesis of DF in X. campestris pv. campestris B24 (Poplawsky et al. 2005). In this study, the xanB2 deletion mutant (designated as $\Delta \mathrm{xanB} 2$ ) of $X$. campestris pv. campestris wild-type strain $\mathrm{XC} 1$ was generated. The mutant $\Delta \mathrm{xanB} 2$ did not produce xanthomonadins and this mutant phenotype was restored by growing $\Delta x a n B 2$ in the vicinity of a wild-type strain, or by adding the supernatant extracts from the overnight culture of wild-type strain XC1 (Fig. 1). Similarly, deletion of xanB2 from $X$. campestris pv. campestris wild-type strain 8004 also resulted in a phenotype almost identical to that of the mutant $\Delta x a n B 2$ (data not shown). These findings confirm that DF signaling is conserved in different $X$. campestris pv. campestris strains and isolates, and that DF has an important role in xanthomonadin biosynthesis.

\section{Purification and structural characterization of DF.}

DF was extracted from bacterial culture supernatants using ethyl acetate and the crude extracts were separated using flashcolumn chromatography and high-performance liquid chromatography (HPLC). A single peak associated with strong DF activity was detected in HPLC elute (Fig. 2A). Approximately $1 \mathrm{mg}$ of pure DF was obtained from 30 liters of culture supernatants, and electrospray ionization (EMI)-MS showed the (molecular weight - 1) of DF to be 137.07 (Supplementary Fig. S1A). Subsequent nuclear magnetic resonance (NMR) analysis suggested the structure of DF to be 3-hydroxybenzoic acid (3-HBA) (Fig. 2C). Further comparison showed that the
${ }^{1} \mathrm{H}$ and ${ }^{13} \mathrm{C}$ NMR spectra of purified DF were virtually indistinguishable from those of commercially available 3-HBA. Consistent with the above findings, addition of commercially available 3-HBA and the purified DF to cultures of $\Delta x a n B 2$ induced similar levels of xanthomonadin biosynthesis (Fig. 1).

\section{DF production during bacterial growth and induction of xanthomonadin biosynthesis.}

Production of DF was not detected until $12 \mathrm{~h}$ postinoculation (Fig. 3A). A sharp DF level increase was observed from 16 to $20 \mathrm{~h}$ of bacterial growth, with the highest level $(5.75 \mu \mathrm{M})$ being detected $28 \mathrm{~h}$ after inoculation (Fig. 3A). Consistent with the trend of DF production, exogenous addition of DF to the culture of DF-minus mutant $\Delta \mathrm{xanB} 2$ at a final concentration of $6.2 \mu \mathrm{M}$ resulted in approximately $82 \%$ of wild-type pigment production (Fig. 3B). Exogenous addition of DF at $12.5 \mu \mathrm{M}$ fully restored the pigment production in $\Delta \mathrm{xanB} 2$ (Fig. $3 \mathrm{~B})$. Further results showed that early xanthomonadin production could be induced at an optical density at $600 \mathrm{~nm}\left(\mathrm{OD}_{600}\right)=$ 1.0 or 1.5 by exogenous addition of $\mathrm{DF}$ at a final concentration of $12.5 \mu \mathrm{M}$ (Fig. 3C). A similar trend was observed in the presence of higher concentrations of DF (data not shown).

\section{Induction of xanthomonadin by DF derivatives.}

To identify the structural features of DF that are important for its biological activity, a variety of commercially available DF analogues were assayed for their abilities to induce xantho-
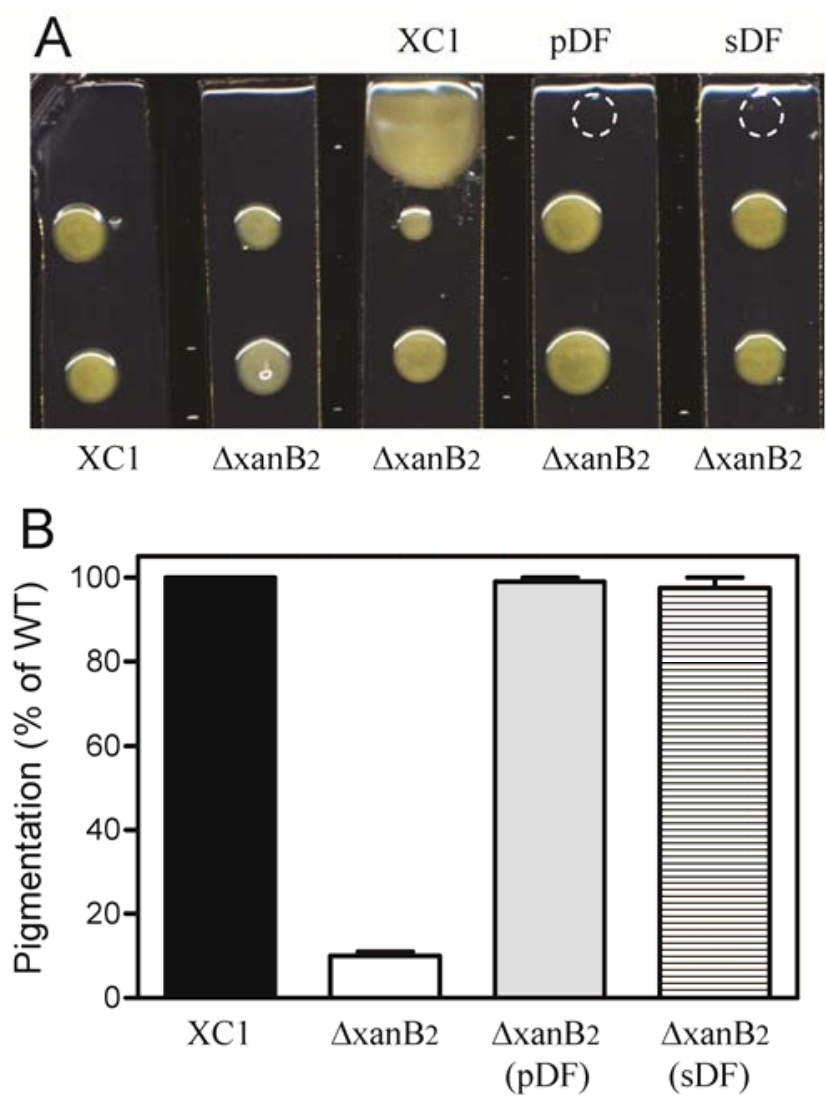

Fig. 1. Diffusible factor (DF) activity in modulation of xanthomonadin biosynthesis. A, Representative diffusion plate assay showing the restoration of xanthomonadin production in DF-deficient mutant $\Delta x a n B 2$ following exposure to Xanthomonas campestris pv. campestris wild-type strain $\mathrm{XC1}$, purified DF, and synthetic DF $(25 \mu \mathrm{M})$ as indicated. B, Quantitative analysis of xanthomonadin production. Purified DF (pDF) and synthetic DF (sDF) were added at a final concentration of $10 \mu \mathrm{M}$. Data are the means of two independent repeats, and error bar indicates standard deviation. 
monadin production. Based on the observation that DF completely restores pigment expression at a concentration of approximately $12.5 \mu \mathrm{M}$ (Fig. 3B), DF and its analogues were tested at a final concentration of $10 \mu \mathrm{M}$ or higher when necessary. Among them, 3-methoxybenzoic acid and 4-amino-3HBA showed approximately 80 and 5\%, respectively, DF-like activity based on assay of pigment restoration (Table 1). In contrast, benzoic acid and salicylic acid (2-hydroxybenzoic acid) had no effect on pigment restoration, even at a concentration of $500 \mu \mathrm{M}$ (Table 1). These data suggest that the hydroxyl group at position 3 of the phenol ring is important for the activity of DF, and amino group substitution at position 4 of the phenol ring compromises its activity.

\section{DF production is widely conserved.}

To determine whether other bacterial pathogens also produce DF, 19 bacterial strains belonging to 15 bacterial species were assayed. DF-like activity was detected in 10 strains of the following eight bacterial species: $X$. campestris pv. campestris, $X$. axonopodis pv. citri, X. oryzae pv. oryzae, X. albilineans, Xylella fastidiosa, Xylophilus ampelinus, Burkholderia cenocepacia J2315, and B. xenovorans LB400 (Supplementary Table $\mathrm{S} 1)$. Interestingly, majority of these strains produce yellow or pink pigments. Furthermore, a Blast search revealed that a range of bacterial species, including Dechloromonas aromatica RCB, Nitrosococcus oceani ATCC 19707, Methylococcus capsulatus Bath, Thiobacillus denitrificans ATCC 25259, B. cenocepacia PC184, Roseobacter sp. strain MED193, Streptomyces
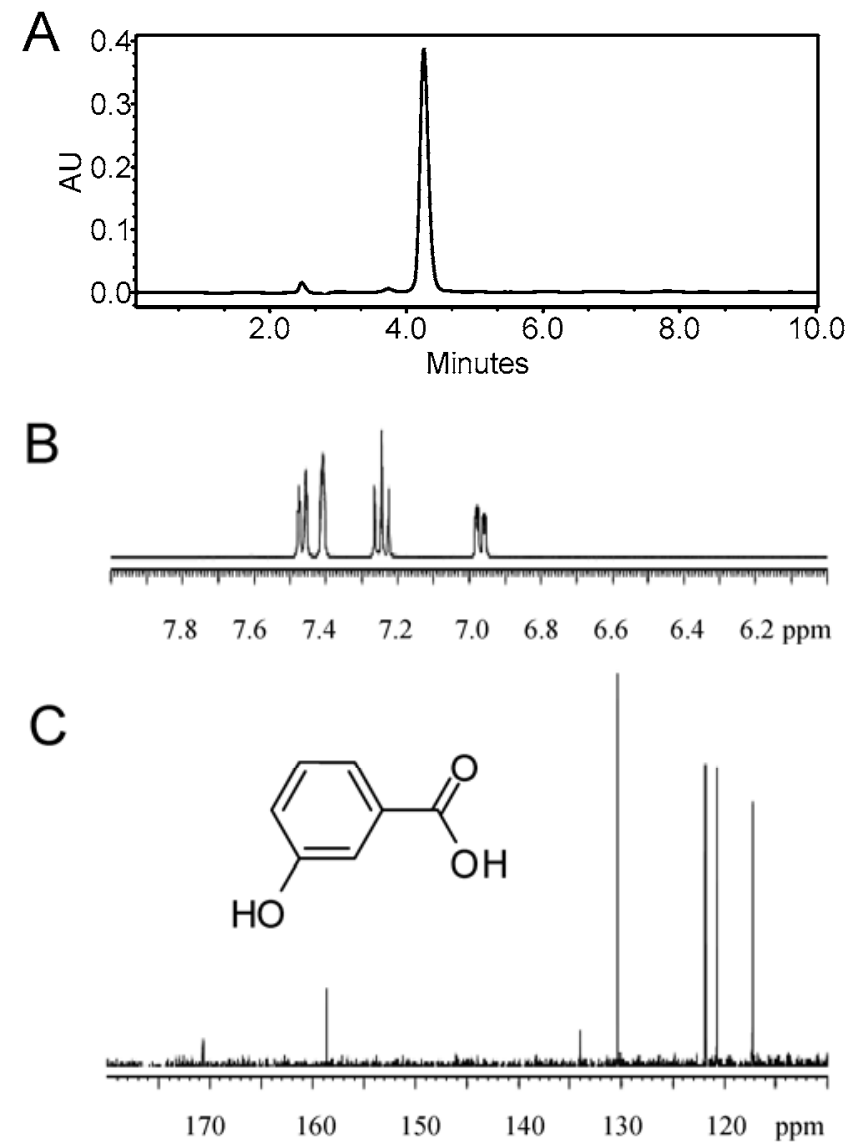

Fig. 2. Diffusible factor (DF) purification and characterization. A, Highperformance liquid chromatography purification of DF following flashcolumn chromatography. The single peak at 4.2 min showed a strong DF activity in bioassay. $\mathbf{B},{ }^{1} \mathrm{H}$ nuclear magnetic resonance (NMR) spectrum of purified DF. C, ${ }^{13} \mathrm{C}$ NMR spectrum of purified DF and the chemical structure of DF (3-hydroxybenzoic acid). hygroscopicus, Granulibacter bethesdensis CGDNIH1, and Verrucomicrobium spinosum DSM 4136 contain the proteins with $>30 \%$ identical amino acids and similar size to XanB2 (Supplementary Fig. S2). The roles of the XanB2 homologues in these bacterial species remains to be investigated.

EPS production by DF-deficient mutant is marginally decreased in the late stationary phase of bacterial growth.

Previous studies of Xanthomonas campestris pv. campestris B24 showed that the DF signal also affects the production of EPS. The DF-deficient mutant derived from strain B24 produced fourfold less EPS than its parent strain on solidified nutrient starch agar (NSA) medium (Poplawsky and Chun 1997). In this study, however, we found that EPS production by DFdeficient strain $\triangle \mathrm{xanB} 2$ was not significantly different from that by $X$. campestris pv. campestris wild-type strains $\mathrm{XC} 1$ or 8004 on the same NSA medium (Supplementary Fig. S3A). EPS production by $X$. campestris pv. campestris wild-type strains XC1 and 8004 were further compared with their corresponding DF-deficient mutants using the sucrose-containing rich YEB medium as previously described (He et al. 2006, 2009). The results showed that both wild-type strains and mutant strains produced similar levels of EPS in the early stationary phase of growth $\left(\mathrm{OD}_{600}=2.0,2.1\right.$, and 2.3). However, at the late stationary phase $\left(\mathrm{OD}_{600}=2.5\right)$, the EPS levels of DFdeficient mutants of $\mathrm{XC1}$ and 8004 were approximately 11.5 and $18.5 \%$, respectively, lower than their corresponding parent strains. Consistent with the above findings, reverse-transcription polymerase chain reaction (PCR) analysis did not reveal any significant differences in the transcriptional levels of gumB and gumK, two genes of the gum operon encoding the key enzymes required for the final step of EPS biosynthesis and secretion (Vorhölter et al. 2008) in X. campestris pv. campestris wild-type and its DF-deficient mutant.

\section{DF production is associated with bacterial survival and $\mathrm{H}_{2} \mathrm{O}_{2}$ resistance.}

To further explore the biological roles of DF, cell viability of wild-type $X$. campestris pv. campestris and the mutant $\Delta \mathrm{xanB} 2$ was compared by counting CFU. No significant difference in CFU was observed between wild-type and DF-deficient mutants during log phase and early stationary phase of bacterial growth $\left(\mathrm{OD}_{600}=1.5,2.0,2.1\right.$, and 2.3) (Supplementary Fig. S5; Fig. 4A). However, the CFU value of the DF-deficient mutant at the late stationary phase $\left(\mathrm{OD}_{600}=2.5\right)$ was significantly lower than that of wild-type XC1 (Fig. 4A). The finding was validated by exogenous addition of DF to cultures of $\triangle \mathrm{xanB} 2$, and the results showed that its $\mathrm{CFU}$ value was restored to the wild-type level (Fig. 4A).

Considering the role of DF in production of the pigment xanthomonadin, which is known for their activity in protecting bacteria against photooxidative stress, we used a pigment-deficient mutant as a control to determine whether DF contributed to bacterial viability directly or indirectly through xanthomonadin. Xcc4015, which encodes a putative AMP ligase, is one of the pig genes required for xanthomonadin biosynthesis in $X$. campestris pv. campestris (da Silva et al. 2002). The Xcc4015 deletion mutant (designated as $\Delta x c c 4015)$ was xanthomonadindeficient (Supplementary Fig. S4). Importantly, this mutant produced a similar level of DF as $X$. campestris pv. campestris wild-type in liquid culture. It was noticed that the CFU values of strain $\Delta x \operatorname{xcc} 4015$ at different growth stages were similar to those of DF-deficient strain $\triangle \mathrm{xanB} 2$, suggesting that the low cell viability phenotype of the DF-minus mutant is probably due to lack of the yellow pigment xanthomonadin.

DF was also found to affect the in vitro survival of bacteria. On sucrose-containing YEB plates (He et al. 2010), the aver- 
age survival time of wild-type strain $\mathrm{XC} 1$ was 24 days at room temperature in darkness whereas the DF-deficient mutant $\Delta \mathrm{xanB} 2$ only survived for 16 days (Fig. 4B). When the culture medium was supplemented with $10 \mu \mathrm{M} \mathrm{DF}$, the survival time of $\Delta \mathrm{xanB} 2$ was substantially increased (Fig. 4B). The survival time of the mutant $\Delta x c c 4015$ was similar to that of DF-deficient strain $\Delta \mathrm{xanB} 2$.
It is known that, along with bacterial growth, active oxygen species accumulate which might cause damage to bacterial cells. To test whether DF production is associated with oxidative stress resistance, the survival rate of $X$. campestris pv. campestris wild-type strain $\mathrm{XC} 1$ and its mutant $\triangle \mathrm{xanB} 2$ after $\mathrm{H}_{2} \mathrm{O}_{2}$ treatment were compared. Bacterial strains were grown in YEB medium until they reached the early stationary phase
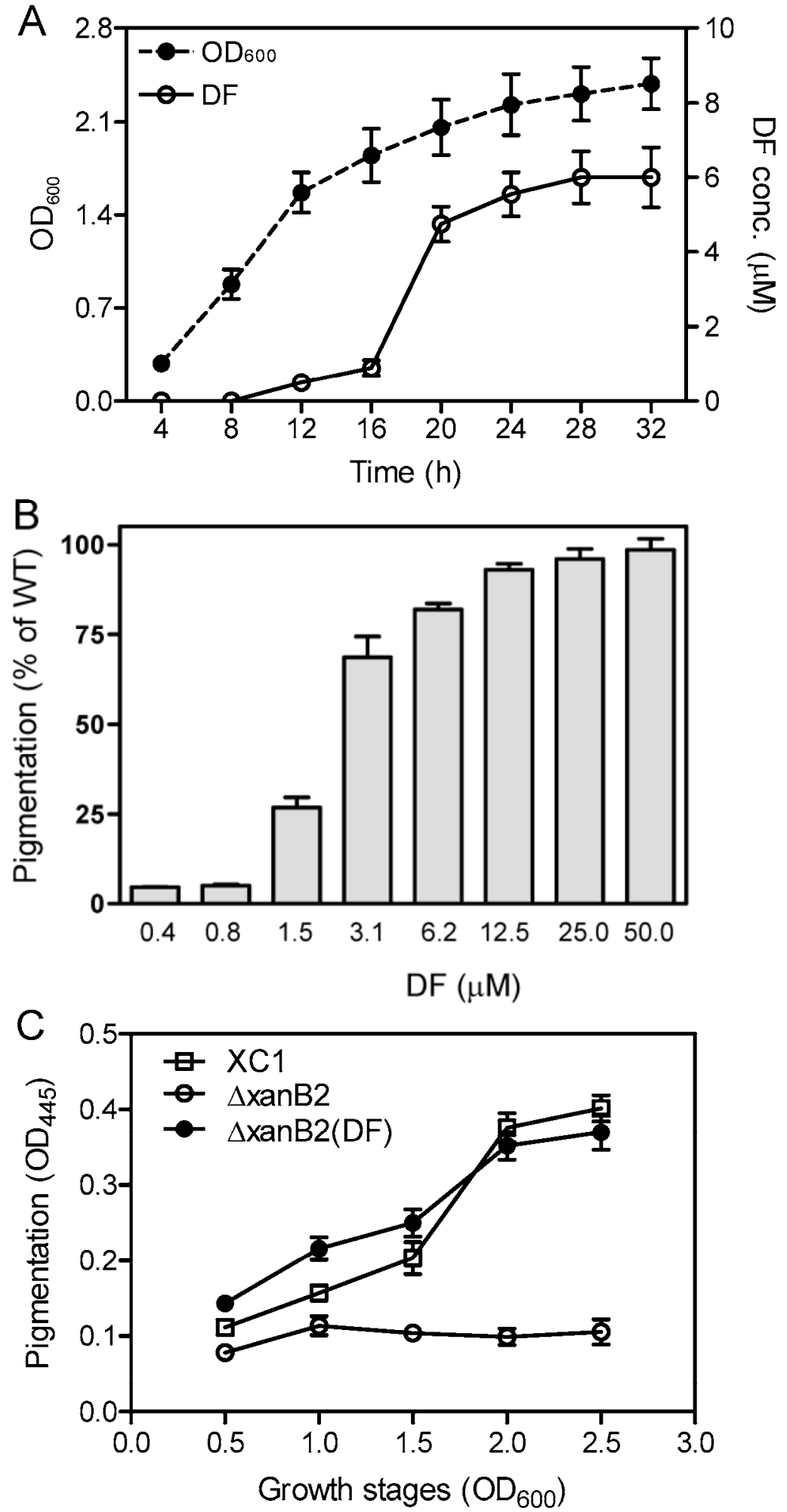

Fig. 3. Time-course analysis of diffusible factor (DF) production and xanthomonadin induction. A, Time course of DF production by strain XC1. B, Dosage effect of DF on xanthomonadin production by DF-deficient mutant $\Delta$ xanB2. C, Time course of xanthomonadin production by DF-deficient strain $\Delta$ xanB2 in the presence of $12.5 \mu \mathrm{M}$ DF. Data presented are the means of two independent repeats and error bars represent standard deviations. 
$\left(\mathrm{OD}_{600}=2.1\right)$. The bacterial cells were precipitated and the pellet was re-suspended in fresh YEB medium. $\mathrm{H}_{2} \mathrm{O}_{2}$ was then added to the cultures at final concentrations of 176,528 , and $880 \mu \mathrm{M}$. After $30 \mathrm{~min}$ of $\mathrm{H}_{2} \mathrm{O}_{2}$ treatment, the $\mathrm{CFU}$ values of each strain were compared. The results showed that abolishment of DF production substantially decreased bacterial resistance to oxidative stress, and addition of DF to cultures of $\Delta \mathrm{xanB} 2$ restored $\mathrm{H}_{2} \mathrm{O}_{2}$ resistance close to the wild-type level (Fig. 5). As a control, strain $\Delta x c c 4015$ was more sensitive to $\mathrm{H}_{2} \mathrm{O}_{2}$ treatment than the $X$. campestris pv. campestris wild-type strain but less than the DF-deficient strain $\triangle$ xanB2 (Fig. 5).

\section{DF-deficient mutant is attenuated in systemic invasion.}

The virulence of wild-type, DF-deficient, and complemented strains was evaluated by measuring lesion lengths 14 days postinoculation on leaves of Chinese radish. Deletion of $x a n B 2$ resulted in a substantial reduction in virulence, which was restored to wild-type levels by in trans expression of $x a n B 2$ (Fig. 6A and B).

$X$. campestris pv. campestris is a vascular pathogen, and its systemic infection of plant tissues correlates with its ability to move and proliferate along the xylems of leaves and stems of infected plants. Given that null mutation of DF production does not affect the production of extracellular enzymes (unpublished data), we speculated that the mutation might affect the bacterial ability in systemic infection. To this end, bacterial progression along the xylem of Chinese cabbage (Wongbok)
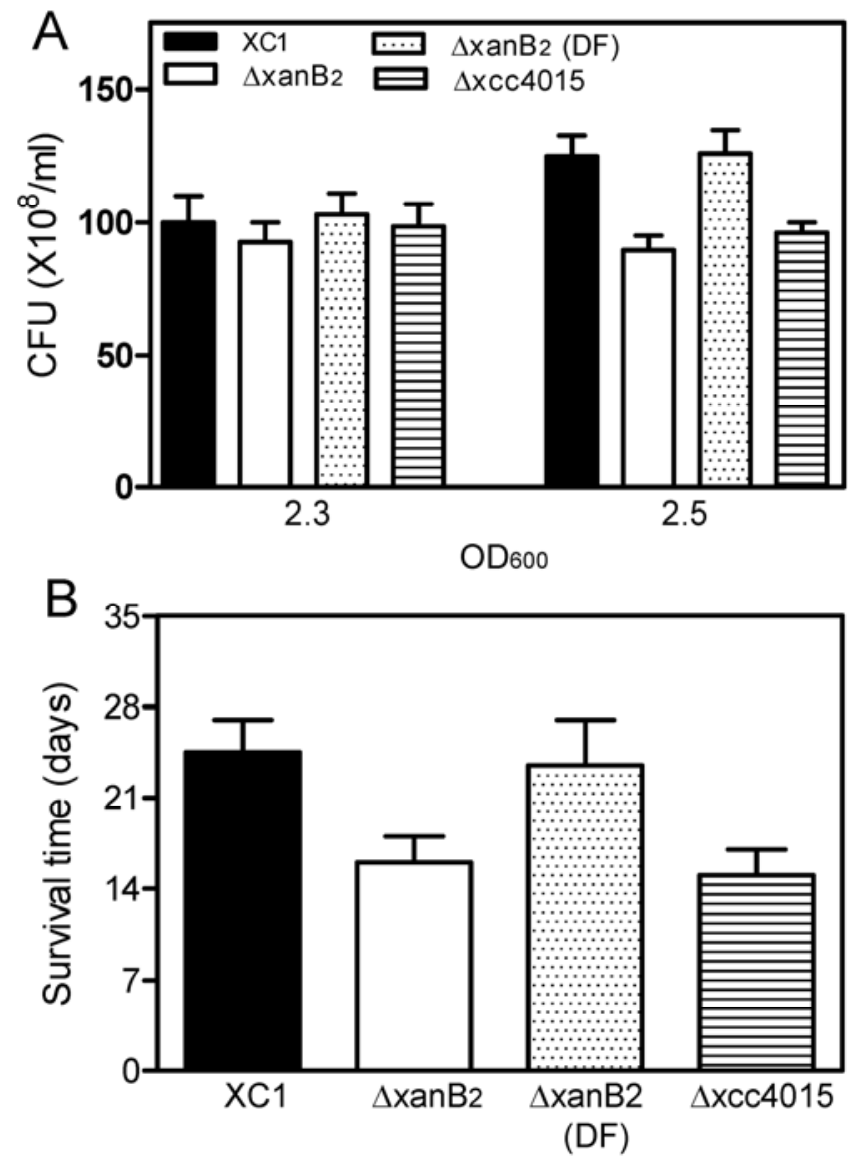

Strains

Fig. 4. Effect of diffusible factor (DF) on bacterial viability. A, Viability of Xanthomonas campestris pv. campestris $\mathrm{XC} 1$, mutant $\Delta \mathrm{xanB} 2$, and $\Delta \mathrm{xcc} 4015$ in the absence or presence of DF at different growth stages in YEB medium. B, In vitro survival on YEB plates. Data are the means of representative duplicates from three independent experiments. was analyzed. One week after inoculation, the average distance of $\Delta x a n B 2$ migration along the infected leaves was approximately $7.5 \mathrm{~cm}$, compared with $10.5 \mathrm{~cm}$ of the wild-type strain (Fig. 6C). As expected, in trans expression of $x a n B 2$ in the DFdeficient mutant resumed its systemic infection ability to the level of wild-type strain (Fig. 6C). The migration ability of strain $\Delta$ xcc4015 was similar to that of $\Delta x a n B 2$ (Fig. $6 C$ ).

\section{DF regulates xanthomonadin production independent of the DSF signaling system.}

DSF is an important quorum-sensing signal involved in the regulation of diverse biological functions such as EPS and exoenzyme production, multidrug resistance, detoxification, aerobic respiration, and flagellar biosynthesis in X. campestris pv. campestris (He and Zhang 2008). To determine whether cross-talk occurs between DF and DSF signaling systems, DF biosynthesis and DF-dependent xanthomonadin production were analyzed in the DSF-deficient strain $\triangle \mathrm{rpfF}$ and in the DSF-overproduction strain $\Delta \mathrm{rpfC}$ (He et al. 2006). The results

Table 1. Biological activity of diffusible factor (DF) and its derivatives
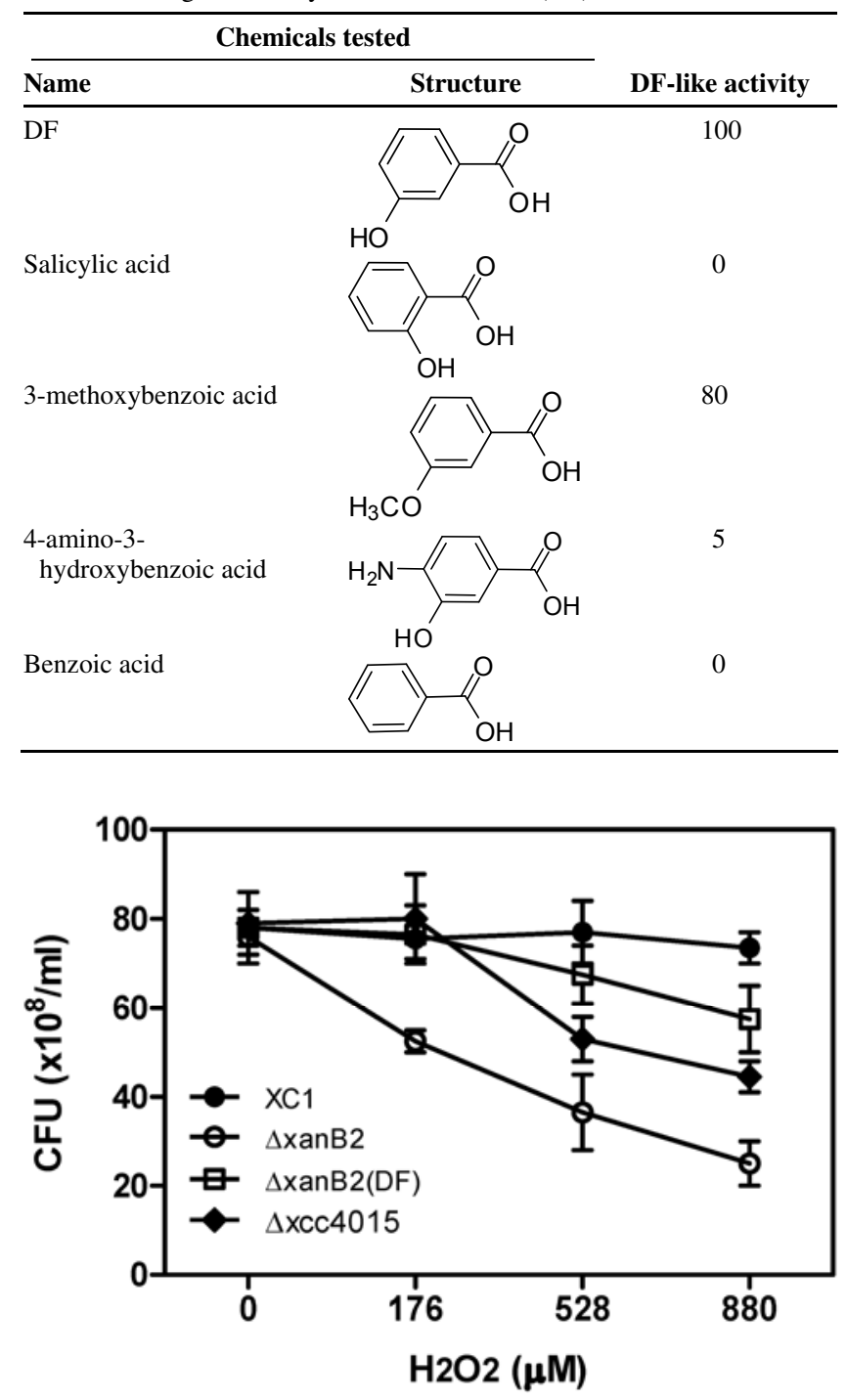

Fig. 5. Diffusible factor (DF) is required for Xanthomonas campestris pv. campestris resistance to oxidative stress. CFU of $X$. campestris pv. campestris wild-type (solid circle), $\Delta \mathrm{xanB} 2$ (open circle), $\Delta \mathrm{xanB} 2+\mathrm{DF}$ (open square), and $\Delta x \operatorname{xc} 4015$ (solid diamond) after $\mathrm{H}_{2} \mathrm{O}_{2}$ treatment. Data are the means of two repeats and the experiment was independently repeated three times. 
showed that deletion of $r p f F$ or $r p f C$ did not affect the production of DF or the DF-dependent pigmentation induction (Supplementary Fig. S6A and B). Furthermore, an $r p f F$ and $x a n B 2$ double-deletion mutant $(\Delta \mathrm{rpfF} \Delta \mathrm{xanB} 2)$ was generated. $\Delta \mathrm{rpfF}$ $\Delta x a n B 2$ strains were deficient in production of DF and DSF signals and did not produce pigment. When $\Delta \operatorname{rpfF} \Delta x a n B 2$ strains were treated with DF, the pigmentation phenotype was restored in the absence of the DSF signal, suggesting that induction of pigment is DSF independent. Similarly, disruption of DF production did not affect DSF biosynthesis $r$ DSFdependent EPS induction (Supplementary Fig. S7).

\section{DF and DSF signaling system have cumulative effects} on bacterial viability, $\mathrm{H}_{2} \mathrm{O}_{2}$ resistance, and systemic invasion.

Using DF- and DSF-deficient mutants and the double-deletion mutant $\Delta \operatorname{rpfF} \Delta x a n B 2$, the contribution of DF and DSF signals to bacterial viability, $\mathrm{H}_{2} \mathrm{O}_{2}$ resistance, and virulence were analyzed. In bacterial viability assays, the wild-type
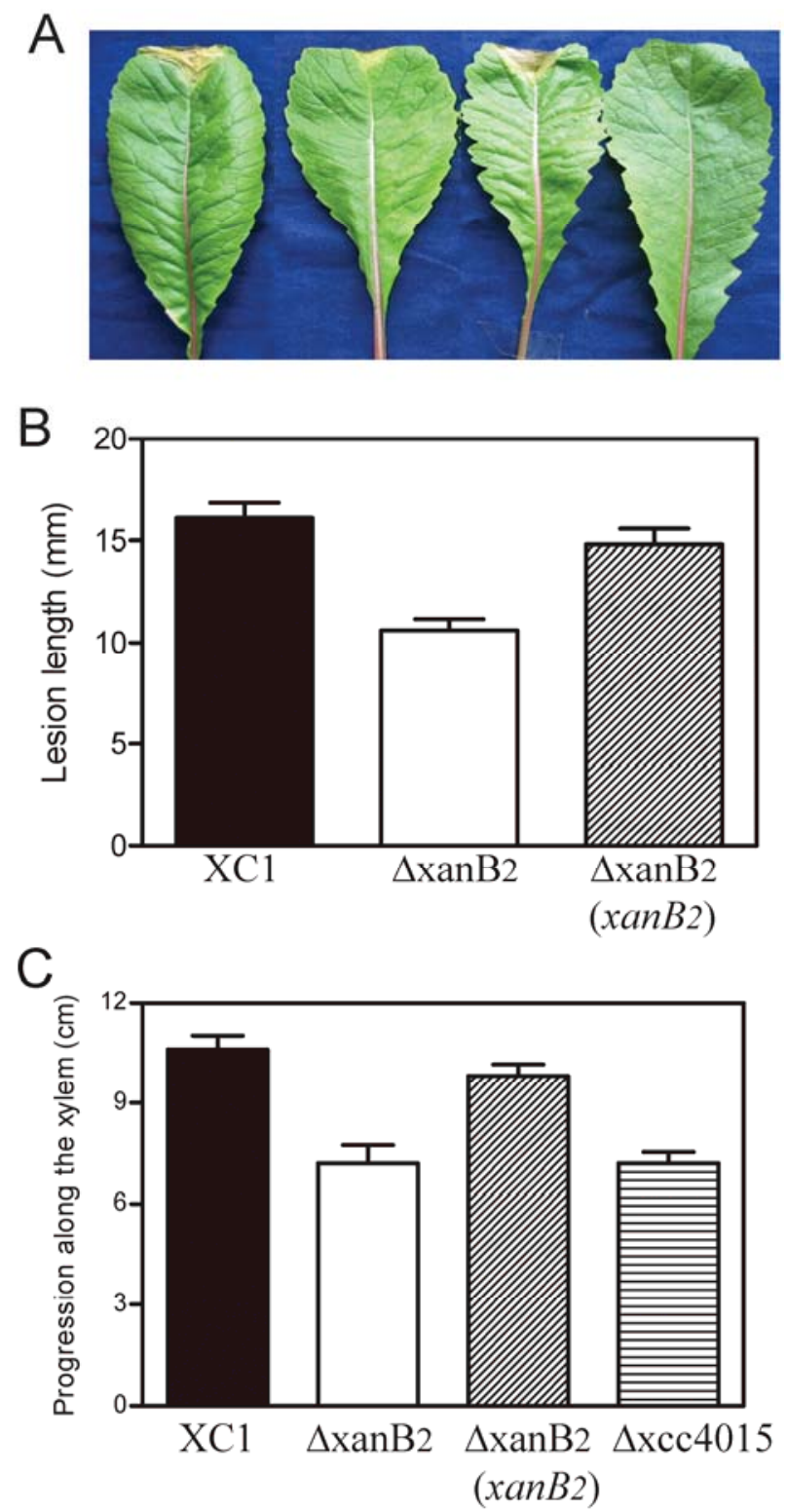

Fig. 6. Disruption of diffusible factor production impaired Xanthomonas campestris pv. campestris virulence and systemic invasion ability. Chinese radish and cabbage were used in $\mathbf{A}$ and $\mathbf{B}$, virulence and $\mathbf{C}$, invasion assays, respectively. Values shown are the mean \pm standard deviation from 10 measurements. strain $\mathrm{XC1}$ and its derivatives were grown in YEB medium until late stationary phase before counting CFU. The results showed that disruption of either DF or DSF production resulted in a decrease in bacterial cell viability (Fig. 7A). The cell viability was further decreased in the double-deletion mutant $\Delta \operatorname{rpfF} \Delta x a n B 2$, which was defective in DF and DSF biosynthesis (Fig. 7A). The mutant $\Delta \mathrm{rpfF} \Delta \mathrm{xanB} 2$ also exhibited the highest sensitivity to $\mathrm{H}_{2} \mathrm{O}_{2}$ compared with the singledeletion mutants $\Delta \mathrm{rpfF}$ or $\Delta \mathrm{xanB} 2$ (Fig. 7B). Consistent with the above findings, $\Delta \operatorname{rpfF} \Delta \mathrm{xanB} 2$ was less virulent than the $\Delta \mathrm{rpfF}$ or $\Delta \mathrm{xanB} 2$ when assayed using Chinese Radish (Fig. 7C). The data support the notion that the DF and DSF signaling system exert cumulative effects in modulating bacterial viability, $\mathrm{H}_{2} \mathrm{O}_{2}$ resistance, and systemic invasion.

\section{DISCUSSION}

A previous study showed that $X$. campestris pv. campestris B24 produces a DF to regulate xanthomonadin production
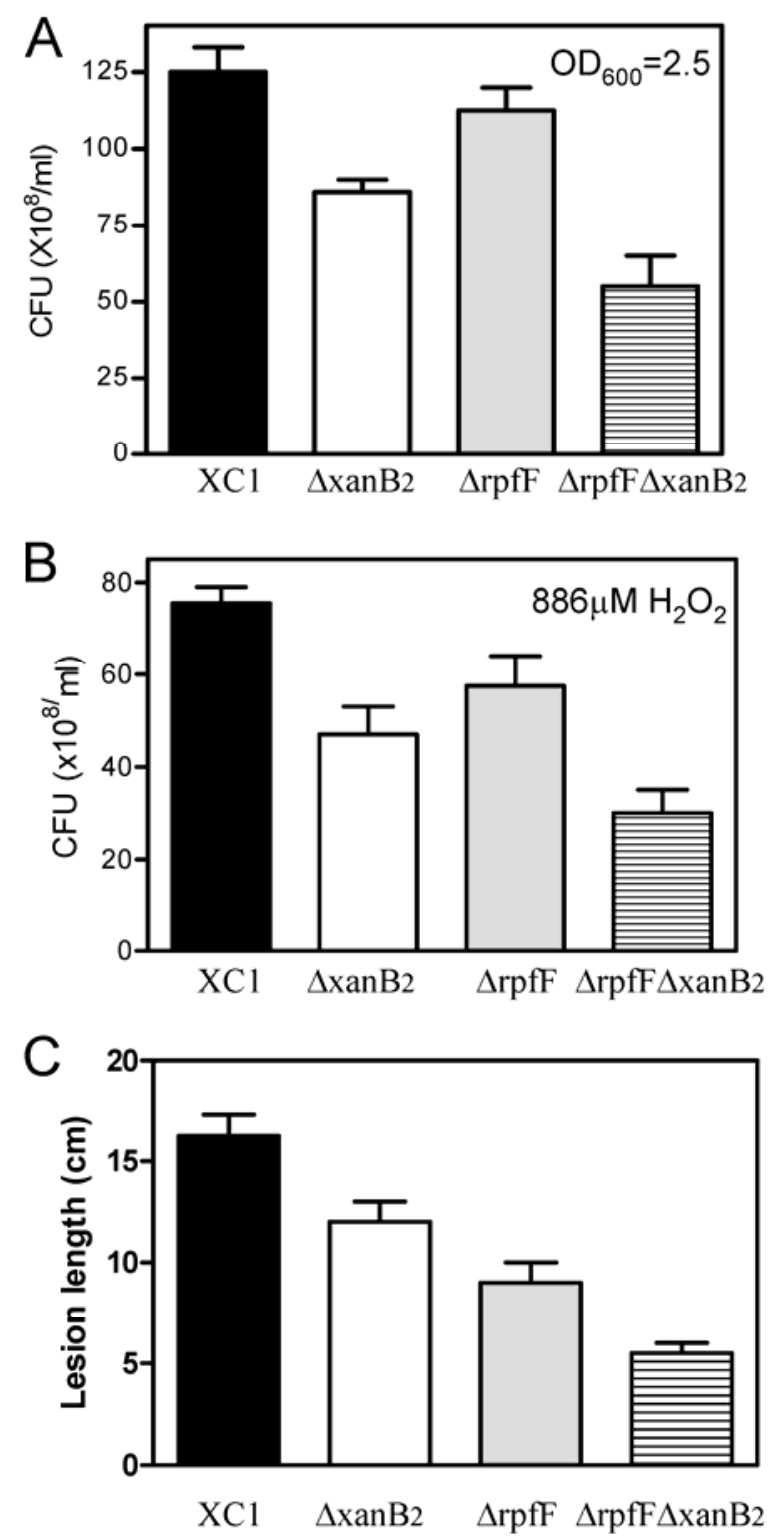

Fig. 7. Diffusible factor and diffusible signaling factor signaling system have cumulative effect on $\mathbf{A}$, bacterial cell viability; $\mathbf{B}, \mathrm{H}_{2} \mathrm{O}_{2}$ resistance; and $\mathbf{C}$, virulence. Values shown are the means \pm standard deviation from two independent experiments. 
(Poplawsky and Chun 1997). Based on MS analysis, it was speculated that DF is a butyrolactone (Chun et al. 1997). In this study, we showed that $X$. campestris pv. campestris strains 8004 and XC1 also produced DF (Fig. 1). The MS and NMR analyses indicated that DF is 3-HBA, which was further confirmed by using synthetic compound and evaluation of biological activity (Fig. 1). Identification of DF chemical structure would facilitate further investigation of its molecular mechanisms in modulation of various biological functions.

DF-like activity has been detected in more than 40 gramnegative bacterial species within the genera Xanthomonas, $X y$ lella, Xylophilus, Streptomyces, and Burkholderia (Poplawsky and Chun 1997; Poplawsky et al. 2005). This list could be further expanded because an in silico analysis identified xanB2 homologues in a range of other bacterial species, including $D$. aromatica, $N$. oceani, $M$. capsulatus, and $T$. denitrificans. These data suggest that production of DF is widely conserved in the bacterial kingdom.

The results from this study showed that DF is associated with diverse biological functions. The DF-deficient mutant $\Delta x a n B 2$ was nonpigmented, impaired in survival ability, and became less virulent than wild-type strain XC1 when assayed against Chinese radish (Fig. 7A). These data are in good agreement with previous findings that DF-deficient pigB mutants derived from $X$. campestris pv. campestris B24 cause fewer lesions on cabbage, and are impaired in epiphytic survival (Poplawsky and Chun 1997, 1998; Poplawsky et al. 1998). In addition, the present study also identified several novel DFdependent biological functions. For example, the DF-deficient mutant was less viable in the late stationary phase (Fig. 4), more sensitive to exogenous $\mathrm{H}_{2} \mathrm{O}_{2}$ (Fig. 5), and attenuated in systemic infection along the xylem tissues of Chinese cabbage (Fig. 6B). It remains unknown how DF is involved in the regulation of these biological functions. Given that there is an aryl group in the structure of xanthomonadin, we speculate that DF, instead of acting as a signal, might be a biosynthetic intermediate for xanthomonadin biosynthesis. Xanthomonadin might account for most, if not all, the observed phenotype changes in the DF-minus mutant, including cell viability, bacterial survival, $\mathrm{H}_{2} \mathrm{O}_{2}$ resistance, and systemic invasion. This hypothesis was supported by several lines of evidences. First, mutation of the gene encoding DF production abolished pigment production (Fig. 1), which is more typical of inactivation of a gene in a biosynthetic pathway than of inactivation of a regulatory gene. Second, although DF production was experimentally confirmed to be associated with EPS production, cell viability and survival, $\mathrm{H}_{2} \mathrm{O}_{2}$ resistance, and systemic invasion, microarray analysis revealed that transcription of the genes encoding these functions were not affected in the DF-deficient mutant (Supplementary Table S2); Third, the Xcc4015 mutant, which was pigment deficient but produced a level of DF similar to that of the wild type, showed patterns in cell viability, $\mathrm{H}_{2} \mathrm{O}_{2}$ resistance, and systemic invasion similar to the DF-deficient mutant (Figs. 3 to 5). Further investigations are needed to elucidate the role of DF in xanthomonadin biosynthesis.

A previous study showed that the DF-deficient pigB mutants derived from $X$. campestris pv. campestris B24 produced fourfold less EPS than their parental wild-type strain on NSA plates (Poplawsky and Chun 1997). However, we did not observe any significant difference in EPS production in $X$. campestris pv. campestris wild-type and DF-deficient strains on NSA plates. By using sucrose-containing YEB medium, we demonstrated that disruption of DF biosynthesis in $X$. campestris pv. campestris strains 8004 and $\mathrm{XC1}$ only marginally affected EPS production at the late stationary phase. Further analysis showed that mutation of the gene for DF production did not affect the transcriptional level of gum operon. Al- though the mechanism behind this difference deserves further investigation, this type of strain-specific variation may not be a total surprise. For example, our previous study showed that null mutation of DSF production in $X$. campestris pv. campestris 8004 caused extensive cell aggregation, whereas the same mutation in strain $\mathrm{XC} 1$ only led to a moderate formation of cell aggregates (He et al. 2006).

Oxidative stress is a common environmental cue that bacterial pathogens encounter in various niches, particularly during the systemic invasion of host organisms. Increasing production of reactive oxygen species, including superoxide, $\mathrm{H}_{2} \mathrm{O}_{2}$, and $\mathrm{OH}$, is associated with aerobic respiration and with active plant defense responses (Bestwick et al. 1997; Bindschedler et al. 2006; Sutherland 1991). X. campestris pv. campestris is a vascular pathogen and is normally restricted to the xylem tissues of infected plants. Therefore, the ability of $X$. campestris pv. campestris to survive oxidative stress is of critical importance for successful colonization in host plants. The DSF-based quorum-sensing system is known to play a role in response to oxidative stress (He et al. 2006, 2007). The results of this study showed that DF also has a role in modulating oxidative stress (Fig. 5). Consistent with the above findings, the double-deletion mutant $\Delta \mathrm{rpfF} \Delta \mathrm{xanB} 2$, which is deficient for DF and DSF signals, was substantially impaired in $\mathrm{H}_{2} \mathrm{O}_{2}$ resistance, systemic invasion, and virulence in Chinese radish (Fig. 6). The previous findings showed that the DSF signal activates the genes encoding multidrug resistance, acriflavin resistance, superoxide dismutase, and catalase (He et al. 2006). In contrast, transcriptional profiling analysis showed that the DF had no effect on expression of the genes encoding the above functions. These results suggest that DF and DSF signals might use different mechanisms to modulate resistance to oxidative stress.

A previous study on $X$. campestris pv. campestris B24 indicates that DF and DSF signaling system are two separate systems with overlapping roles in regulation of EPS production (Poplawsky et al. 1998). This study has provided further evidence for the roles of DF and the DSF signaling system in comodulation of bacterial viability, survival, and $\mathrm{H}_{2} \mathrm{O}_{2}$ resistance (Fig. 7). Bacterial pathogens commonly evolve and adopt an array of mechanisms to modulate virulence. Utilization of multiple signaling systems by $X$. campestris pv. campestris may confer considerable flexibility in expressing specific sets of genes required for adaptation and survival in response to changing environmental conditions. Identification of the chemical structure of DF would facilitate future studies on this intriguing and widely conserved molecule; much remains to be done to understand the roles and mechanisms of DF in $X$. campestris pv. campestris physiology and virulence.

In general, the findings in this study have not only laid down a valuable framework for designing and developing novel strategies against bacterial infections, such as quorum quenching or competitive inhibition, but also presented many intriguing questions for further investigations. For example, little is known of how DF is synthesized in $X$. campestris pv. campestris, and it remains unclear how DF is involved in the regulation of diverse functions; in particular, xanthomonadin biosynthesis. In addition, the fascinating findings that production of DF is conserved in a wide range of bacterial species, especially in human pathogens and ocean microorganisms, may substantially broaden the scope of investigation on DF.

\section{MATERIALS AND METHODS}

\section{Bacterial strains and growth conditions.}

$X$. campestris pv. campestris wild-type strains $\mathrm{XC1}$ and 8004 , and their derivatives were grown at $28^{\circ} \mathrm{C}$ in NYG $(5 \mathrm{~g}$ of peptone, $3 \mathrm{~g}$ of yeast extract, and $20 \mathrm{~g}$ of glycerol, $\mathrm{pH} 7.0$ ) or 
YEB (5 $\mathrm{g}$ of yeast extract, $10 \mathrm{~g}$ of tryptone, $5 \mathrm{~g}$ of sodium chloride, $5 \mathrm{~g}$ of sucrose, and $0.5 \mathrm{~g}$ of $\mathrm{MgSO}_{4}$ ) media in the dark. Escherichia coli strains were grown at $37^{\circ} \mathrm{C}$ in LuriaBertani medium. Antibiotics were added at the following concentrations when required: kanamycin at $50 \mathrm{mg} \mathrm{ml}^{-1}$, gentamicin at $50 \mathrm{mg} \mathrm{ml}^{-1}$, rifampicin at $25 \mathrm{mg} \mathrm{ml}^{-1}$, ampicillin at $100 \mathrm{mg} \mathrm{ml}^{-1}$, and tetracycline at $5 \mathrm{mg} \mathrm{ml}^{-1} ; 5$-bromo-4-chloro3 -indolyl $\beta$-D-glucopyranoside at $60 \mathrm{mg} \mathrm{ml}^{-1}$ was included for detection of $\beta$-glucuronidase activity.

\section{Gene deletion and functional complementation analysis.}

Xcc4014 in-frame deletion mutants of X. campestris pv. campestris strains 8004 and XC1 were generated according to $\mathrm{He}$ and associates (2006) using the following primers: 4014FOR1: cgaggacgccggcaacatca, 4014-REV1: gggatcccagtggcac gcgcaaatagc, 4014-FOR2: cgggatccgacggcgtgcacggctgagt, and 4014-REV2: ccgccgctggtaggcatcgtc. Xcc4014 and rpfF doubledeletion mutants were generated using mutant $\Delta \mathrm{rpfF}$ as the parental strain and the same primers listed above. For complementation analysis, the coding region of Xcc4014 was amplified by PCR using: Xcc4014-FOR (cgggatccegtgttccgcgecatct attc) and Xcc4014-REV (cccaagctttcagccgtgcacgecgtcgat), and was cloned under the control of lac promoter in pLAFR3. The resulting construct was transferred into $X$. campestris pv. campestris strains through triparental mating. The $X c c 4014$ deletion mutant was further verified by PCR and sequencing analysis.

\section{Extraction and quantification of pigment.}

The procedure described previously (Irey and Stall 1982) for extraction of pigment from $X$. juglandis was used in this study with minor modifications. Briefly, X. campestris pv. campestris cultures were grown until the stationary phase $\left(\mathrm{OD}_{600}=\right.$ 2.3), and the cells from $5 \mathrm{ml}$ of culture were collected by centrifugation. Pigments were extracted with $1 \mathrm{ml}$ of methanol by shaking for $5 \mathrm{~min}$ at room temperature. The amount of pigment produced was expressed as the absorbance (OD at 445 $\mathrm{nm}$ ) of crude pigment extracts (Poplawsky and Chun 1997).

\section{Bioassay of DF.}

The presence of DF was indicated by its effect on the restoration of pigment in DF-deficient mutant $\Delta x a n B 2$. Two methods were developed to detect the DF signal in this study. For qualitative detection of DF, $15 \mathrm{ml}$ of NYG medium containing $0.8 \%$ agarose were poured into a sterilized plastic petri dish $(90 \mathrm{~mm}$; Sterilin, Newport, U.K.). After solidification, the agarose plates were aseptically cut into separated rectangular bars of 1 $\mathrm{cm}$ in width by removing approximately $2-\mathrm{mm}$ slices between the bars. Bacterial cells, or 10- $\mu$ l extracts or purified DF dissolved in methanol, were added to the upper end of agarose bars. Drops of $\Delta \mathrm{xanB} 2$ cell culture $\left(\mathrm{OD}_{600}=0.05\right)$ were then spotted at progressively further distances from the end of agarose bars loaded with the DF sample or bacterial strain to be tested. The resulting plates were sealed and incubated at $30^{\circ} \mathrm{C}$ for 2 days. The presence of yellow-colored bacterial spots indicated the activity of DF. For quantitative analysis of DF, mutant $\Delta x a n B 2$ was grown in $5 \mathrm{ml}$ of NYG liquid medium until an $\mathrm{OD}_{600}$ of 1.0. DF samples were then added as indicated and the bacterial cultures were grown for another $8 \mathrm{~h}$ to an $\mathrm{OD}_{600}$ of 2.3. Cells were collected by centrifugation at 10,000 rpm for $5 \mathrm{~min}$ and pigments were extracted using $1 \mathrm{ml}$ of methanol (Irey and Stall 1982). The amount of pigment produced was determined by measuring absorbance at $445 \mathrm{~nm}$ (Poplawsky and Chun 1997). The percentage (P) of pigment restored by $\mathrm{DF}$ was defined as the $\mathrm{OD}_{445}$ of DF-treated $\triangle \mathrm{xanB} 2$ cultures divided by that of the wild-type strain and multiplied by 100 . The quantity of DF was calculated using the formula $\mathrm{DF}(\mu \mathrm{M})=0.0741 \mathrm{e}^{0.0507 \mathrm{P}}$, which was derived from a dose-response plot of the biosensor $\Delta \mathrm{xanB} 2$ to DF, with a correlation coefficiency $\left(R^{2}\right)$ of 0.98 .

\section{Purification and structural analysis of DF.}

$X$. campestris pv. campestris XC1 was cultured in NYG medium for $32 \mathrm{~h}$. Bacterial supernatants (30 liters total) were collected by centrifugation $\left(3,800 \mathrm{rpm}\right.$ for $30 \mathrm{~min}$ at $\left.4^{\circ} \mathrm{C}\right)$. The supernatants were adjusted to $\mathrm{pH} 4.0$ by addition of $1 \mathrm{M}$ hydrochloride prior to extraction with an equal volume of ethyl acetate. The extraction was repeated twice and the extracts were combined and dried using rotary evaporation at $40^{\circ} \mathrm{C}$. The resulting residues were dissolved in $20 \mathrm{ml}$ of methanol. The crude extracts, divided into four batches, were subjected to flash-column chromatography using a silica gel column (12 by $150 \mathrm{~mm}$; Biotage Flash 12M cartridge) eluted with ethyl acetate-hexane (25:75, vol/vol, $0.05 \%$ acetic acid) mixture. The active fractions were combined and were further separated by using HPLC with a C18 reverse-phase column (4.6 by 250 $\mathrm{mm}$; Phenomenex Luna) eluted with methanol-water (30:70, $\mathrm{vol} / \mathrm{vol}, 0.05 \%$ acetic acid) at a flow rate of $1 \mathrm{ml} / \mathrm{min}$ in a Waters 2695 system with 996 PDA detector. Purified DF was subjected to ESI-MS analysis (Finnigan LCQ system). For NMR analysis, the purified DF was dissolved in methanol-d4 and ${ }^{1} \mathrm{H}$ and ${ }^{13} \mathrm{C}$ spectra were recorded on a Bruker DRX400 $400 \mathrm{MHz}$ spectrometer at room temperature. The chemical shifts $(\delta)$ were quoted in parts per million (ppm), and the coupling constant $(\mathrm{J})$ values were recorded in $\operatorname{Hertz}(\mathrm{Hz})$.

\section{Time-course analysis of DF production.}

The relationship between bacterial population density and DF production was examined by sampling cell culture at different stages of bacterial growth. X. campestris pv. campestris $\mathrm{XC1}$ was grown in $1,000 \mathrm{ml}$ of NYG broth with shaking at $28^{\circ} \mathrm{C}$. Samples (50 ml) were collected at 4, 8, 12, 16, 20, 24, 28, 32, and $36 \mathrm{~h}$ after inoculation and DF was extracted as described above. After evaporation, the residues were dissolved in $100 \mu \mathrm{l}$ of methanol, and 10- $\mu$ l aliquots were added to $5 \mathrm{ml}$ of $\Delta \mathrm{xanB} 2$ cell cultures for quantitative analysis of DF as described above.

\section{$\mathrm{H}_{2} \mathrm{O}_{2}$ sensitivity and bacterial viability test.}

$X$. campestris pv. campestris strains were grown in YEB medium with or without DF to an $\mathrm{OD}_{600}$ of 2.1. The cultures were then diluted with fresh YEB medium to an $\mathrm{OD}_{600}$ of 0.1 . Bacterial suspensions were treated with 176,528 , and $880 \mu \mathrm{M}$ $\mathrm{H}_{2} \mathrm{O}_{2}$ for 30 min. Bacterial cells were then spun down and washed once in phosphate buffer (50 mM, pH 7.4). Cells were serially diluted and spotted onto YEB agar plates, then incubated at $30^{\circ} \mathrm{C}$ for 2 days before counting CFU. The experiment was repeated three times.

For bacterial viability testing, the wild type and mutant $\triangle \mathrm{xanB} 2$ were subcultured in YEB liquid medium with or without $\mathrm{DF}$ as indicated. Bacterial viability at $\mathrm{OD}_{600}=1.5,2.0,2.3$, and 2.5 was determined by plate-counting of CFU. For determination of survival time, the wild type and xanB2 mutant were subcultured on YEB agar plate with or without DF as indicated. After growth at $30^{\circ} \mathrm{C}$ for 2 days, the agar plates were maintained at room temperature in the dark. From the seventh day onward, the viability of cells was tested every 2 days by subculture of three randomly selected colonies from each treatment on fresh YEB plate. Growth of bacterial cells was monitored for 2 days at $30^{\circ} \mathrm{C}$. Loss of viability was further confirmed by growing five colonies per treatment in liquid YEB medium, separately.

\section{Bioassays and virulence test.}

DSF bioassay was performed as previously described (Wang et al. 2004). Extracellular cellulase and protease activity were 
analyzed as described by He and associates (2009). To analyze the production of EPS, the supernatants of overnight bacterial culture in YEB medium (10 ml, $\mathrm{OD}_{600}$ of approximately 2.3$)$ were collected by centrifugation at $10,000 \mathrm{rpm}$ for $10 \mathrm{~min}$. Two volumes of absolute ethanol were added the supernatants and the mixtures were kept at $-20^{\circ} \mathrm{C}$ for a half-hour. The precipitated EPS were spun down and dried in a $55^{\circ} \mathrm{C}$ oven overnight before determination of dry weights. Cell aggregation assay and virulence tests were conducted according to the scissors-clipping method described previously (He et al. 2006, 2009). Oligomicroarray analysis was conducted according to the methods described previously (He et al. 2006). The total RNAs were extracted from bacterial cells at $\mathrm{OD}_{600}=2.3$.

\section{Assay for bacterial systemic invasion.}

Fully matured Chinese cabbage (Wongbok) leaves were used for the assay. The bottom part (approximately $1 \mathrm{~cm}$ ) of each leaf was cut off and the resulting wound was immediately immersed in fresh $\mathrm{XC} 1$ bacterial culture $\left(\mathrm{OD}_{600}=0.1\right)$ for $5 \mathrm{~s}$. The inoculated leaf was then wrapped with plastic film and kept in an incubator at $25^{\circ} \mathrm{C}$ with $80 \%$ humidity for a week. The infected leaf was marked every $2 \mathrm{~cm}$ from the inoculated end, and a slice of tissue $(0.2$ by $1.0 \mathrm{~cm})$ was taken out at each mark for sap extraction. The extracted sap was serially diluted and $100 \mu \mathrm{l}$ of each dilution was spread on an agar plate containing rifampicin $(25 \mu \mathrm{g} / \mathrm{ml})$ for colony counting. For each treatment, 10 leaves were used and three independent experiments were performed.

\section{ACKNOWLEDGMENTS}

This research was supported by funding from the Agency for Science, Technology and Research (A*STAR), Singapore and Shanghai Jiao Tong University, China.

\section{LITERATURE CITED}

Andrewes, A. G., Jenkins, C. L., Starr, M. P., Shepherd, J., and Hope, H. 1976. Structure of xanthomonadin I, a novel dibrominated aryl-polyene pigment produced by the bacterium Xanthomonas juglandis. Tetrahedron Lett. 45:4023-4024.

Bestwick, C. S., Brown, I. R., Bennett, M. H. R., and Mansfield, J. W. 1997. Localization of hydrogen peroxide accumulation during the hypersensitive reaction of lettuce cells to Pseudomonas syringae pv. phaseolicola. Plant Cell 9:209-221.

Bindschedler, L. V., Dewdney, J., Blee, K. A., Stone, J. M., Asai, T., Plotnikov, J., Denoux, C., Hayes, T., Gerrish, C., Davies, D. R., et al. 2006. Peroxidase dependent apoplastic oxidative burst in Arabidopsis required for pathogen resistance. Plant J. 47:851-863.

Chun, W., Cui, J., and Poplawsky, A. R. 1997. Purification, characterization and biological role of a pheromone produced by Xanthomonas campestris pv. campestris. Physiol. Mol. Plant Pathol. 51:1-14.

da Silva, A. C., Ferro, J. A., Reinach, F. C., Farah, C. S., Furlan, L. R., Quaggio, R. B., Monteiro-Vitorello, C. B., Van Sluys, M. A., Almeida, N. F., Alves, L. M., do Amaral, A. M., Bertolini, M. C., Camargo, L. E., Camarotte, G., Cannavan, F., Cardozo, J., Chambergo, F., Ciapina, L. P., Cicarelli, R. M., Coutinho, L. L., Cursino-Santos, J. R., El-Dorry, H., Faria, J. B., Ferreira, A. J., Ferreira, R. C., Ferro, M. I., Formighieri, E. F., Franco, M. C., Greggio, C. C., Gruber, A., Katsuyama, A. M., Kishi, L. T., Leite, R. P., Lemos, E. G., Lemos, M. V., Locali, E. C., Machado, M. A., Madeira, A. M., Martinez-Rossi, N. M., Martins, E. C., Meidanis, J., Menck, C. F., Miyaki, C. Y., Moon, D. H., Moreira, L. M., Novo, M. T., Okura, V. K., Oliveira, M. C., Oliveira, V. R., Pereira, H. A., Rossi, A., Sena, J. A., Silva, C., de Souza, R. F., Spinola, L. A., Takita, M.A., Tamura, R. E., Teixeira, E. C., Tezza, R. I., Trindade dos Santos, M., Truffi, D., Tsai, S. M., White, F. F., Setubal, J. C., and Kitajima, J. P. 2002. Comparison of the genomes of two Xanthomonas pathogens with differing host specificities. Nature 417:459-463.

Durgapal, J. C. 1996. 'Albino' mutation in rice bacterial blight pathogen. Curr. Sci. 70:15.

Goel, A. K., Rajagopal, 1., Nagesh, N., and Sonti, R. V. 2002. Genetic locus encoding functions involved in biosynthesis and outer membrane localization of xanthomonadin in Xanthomonas oryzae pv. oryzae. J. Bacte- riol. 184:3539-3548.

He, Y. W., and Zhang, L. H. 2008. Quorum sensing and virulence regulation in Xanthomonas campestris. FEMS (Fed. Eur. Microbiol. Soc.) Microbiol. Rev. 32:842-857.

He, Y. W., Xu, M., Lin, K., Ng, Y. J., Wen, C. M., Wang, L. H., Liu, Z. D., Zhang, H. B., Dong, Y. H., Dow, J. M., and Zhang, L. H. 2006. Genome scale analysis of diffusible signal factor regulon in Xanthomonas campestris pv. campestris: identification of novel cell-cell communication-dependent genes and functions. Mol. Microbiol. 59:610-622.

He, Y. W., Ng, A. Y., Xu, M., Lin, K., Wang, L. H., Dong, Y. H., and Zhang, L. H. 2007. Xanthomonas campestris cell-cell communication involves a putative nucleotide receptor protein Clp and a hierarchical signalling network. Mol. Microbiol. 64:281-292.

He, Y. W., Boon, C., Zhou, L., and Zhang, L. H. 2009. Co-regulation of Xanthomonas campestris virulence by quorum sensing and a novel twocomponent regulatory system RavS/RavR. Mol. Microbiol. 71:14641476.

He, Y. W., Wu, J. E., Cha, J. S., and Zhang, L. H. 2010. Rice bacterial blight pathogen Xanthomonas oryzae pv. oryzae produces multiple DSF-family signals in regulation of virulence factor production. BMC Microbiol. 10: 187.

Irey, M. S., and Stall, R. E. 1982. Value of xanthomonadins for identification of pigmented Xanthomonas campestris pathovars. Pages 85-95 in: Proc. Fifth International Conference on Plant-Pathogenic Bacteria. Cali, Columbia.

Jenkins, C. L., and Starr, M. P. 1982.The pigment of Xanthomonas populi is a nonbrominated aryl-heptaene belonging to xanthomonadin pigment group II. Curr. Microbiol. 7:195-198.

Leyns, F., De Cleene, M., Swings, J., and de Ley, J. 1984. The host range of the genus Xanthomonas. Bot. Rev. 50:308-355.

Poplawsky, A. R., and Chun, W. 1997. pigB determines a diffusible factor needed for extracellular polysaccharide slime and xanthomonadin production in Xanthomonas campestris pv. campestris. J. Bacteriol. 179:439-444.

Poplawsky, A. R., and Chun, W. 1998. Xanthomonas campestris pv. campestris requires a functional pigB for epiphytic survival and host infection. Mol. Plant-Microbe Interact. 11:466-475.

Poplawsky, A. R., Kawalek, M. D., and Schaad, N. W. 1993. A xanthomonadin-encoding gene cluster for the identification of pathovars of Xanthomonas campestris. Mol. Plant-Microbe Interact. 6:545-552.

Poplawsky, A. R., Chun, W, Slater, H., Daniels, M. J., and Dow, J. M. 1998. Synthesis of extracellular polysaccharide, extracellular enzymes, and xanthomonadin in Xanthomonas campestris: evidence for the involvement of two intercellular regulatory signals. Mol. Plant-Microbe Interact. 11:68-70.

Poplawsky, A. R., Urban, S. C., and Chun, W. 2000. Biological role of xanthomonadin pigments in Xanthomonas campestris pv. campestris. Appl. Environ. Microbiol. 66:5123-5127.

Poplawsky, A. R., Walters, D. M., Rouviere, P. E., and Chun, W. 2005. A gene for a dioxygenase-like protein determines the production of the DF signal in Xanthomonas campestris pv. campestris. Mol. Plant Pathol. 6:653-657.

Qian, W., Jia, Y., Ren, S. X., He, Y. Q., Feng, J. X., Lu, L. F., Sun, Q., Ying, G., Tang, D. J., Tang, H., Wu, W., Hao, P., Wang, L., Jiang, B. L., Zeng, S., Gu, W. Y., Lu, G., Rong, L., Tian, Y., Yao, Z., Fu, G., Chen, B., Fang, R., Qiang, B., Chen, Z., Zhao, G. P., Tang, J. L., and He, C. 2005. Comparative and functional genomic analyses of the pathogenicity of phytopathogen Xanthomonas campestris pv. campestris. Genome Res. 15:757-767.

Rajagopal, L., Sundari, C. S., Balasubramanian, D., and Sonti, R. V. 1997. The bacterial pigment xanthomonadin offers protection against photodamage. FEBS (Fed. Eur. Biochem. Soc.) Lett. 415:125-128.

Schaad, N. W., and Stall, R. E. 1988. Xanthomonas. Pages 81-94 in: Laboratory Guide for Identification of Plant Pathogenic Bacteria, 2nd ed. N. W. Schaad, ed. American Phytopathological Society Press, St. Paul, MN, U.S.A.

Starr, M. P. 1981. The genus Xanthomonas. Pages 742-763 in: The Prokaryotes, Vol. 1. M. P. Starr, H. Stolp, G. H. Truper, A. Balows, and G H. Schlegel, eds. Springer-Verlag, Berlin.

Starr, M. P., and Stephens, W. L. 1964. Pigmentation and taxonomy of the genus Xanthomonas. J. Bacteriol. 87:293-302.

Starr, M. P., Jenkins, C. L., Bussey, L. B., and Andrewes, A. G. 1977. Chemotaxonomic significance of the xanthomonadins, novel brominated aryl-polyene pigments produced by bacteria of the genus Xanthomonas. Arch. Microbiol. 113:1-9.

Stephens, W. L., and Starr, M. P. 1963. Localization of carotenoid pigment in the cytoplasmic membrane of Xanthomonas juglandis. J. Bacteriol. 86:1070-1074.

Sutherland, M. W. 1991. The generation of oxygen radicals during host 
plant responses to infection. Physiol. Mol. Plant Pathol. 39:79-93.

Tsuchiya, K., Mew, T. W., and Wakimoto, S. 1982. Bacteriological and pathological characteristics of wild-type and induced mutants of Xanthomonas campestris pv. oryzae. Phytopathology 72:43-46.

Vorhölter, F. J., Schneiker, S., Goesmann, A., Krause, L., Bekel, T., Kaiser, O., Linke, B., Patschkowski, T., Rückert, C., Schmid, J., Sidhu, V. K., Sieber, V., Tauch, A., Watt, S. A., Weisshaar, B., Becker, A., Niehaus, K., and Pühler, A. 2008. The genome of Xanthomonas campestris pv. campestris B100 and its use for the reconstruction of metabolic path- ways involved in xanthan biosynthesis. J. Biotechnol. 134:33-45.

Wang, L. H., He, Y. W., Gao, Y., Wu, J. E., Dong, Y. H., He, C., Wang, S. X, Weng, L. X., Xu, J. L. Tay, L., Fang R. X., and Zhang, L. H. 2004. A bacterial cell-cell communication signal with cross-kingdom structural analogues. Mol. Microbiol. 51:903-912.

Yajima , A., Imai, N., Poplawsky, A. R., Nukada, T., and Yabuta, G. 2010. Synthesis of a proposed structure for the diffusible extracellular factor of Xanthomonas campestris pv. campestris. Tetrahedron Lett. 51:20742077. 